\title{
Drug dosing in obese adults
}

\section{SUMMARY}

Drug doses often warrant adjustment in obese patients.

Clinicians should consider the patient's body composition when calculating doses. Drug clearance is greater in obesity and correlates with lean body weight.

Body size metrics help guide dose selection, but there are advantages and disadvantages to all of them.

Chronic dosing using total body weight can lead to drug toxicity.

Studies evaluating weight-based dosing strategies are required for many drugs.

\section{Introduction}

In Australia and internationally, approximately $30 \%$ of adults are obese, and $65 \%$ are either overweight or obese., ${ }^{1,2}$ There is little evidence and guidance on how best to dose these individuals.

Few studies have quantified the influence of body size on the pharmacokinetics or pharmacodynamics of many common drugs. ${ }^{3}$ Generally, licensed dosing recommendations are based on clinical trials in which people with obesity are under-represented or excluded and evidence-based dosing guidelines are lacking. ${ }^{3}$ This may result in arbitrary dose selection leading to therapeutic failure or drug toxicity.

A fixed strategy in which all patients receive the same dose remains a common form of drug dosing. However, significant variations in pharmacokinetic and pharmacodynamic responses can occur between patients due to weight, age, genetics, concurrent diseases and other factors. ${ }^{4-7}$ Ideally, the 'one dose fits all' paradigm should be replaced by individualised dosing methods.

Drug doses are usually calculated using a patient's total body weight. This is often inappropriate for obese patients, and clinicians may therefore dose using an alternative body size descriptor. Close monitoring of the patient's clinical response and therapeutic drug monitoring (if available) is important.

Drugs that commonly require dose adjustment in obese patients include low-molecular-weight heparins, ${ }^{8}$ aminoglycoside antibiotics, ${ }^{9}$ some anaesthetics, ${ }^{10}$ monoclonal antibodies and chemotherapeutics."1

\section{Body weight}

Body size is typically defined using body mass index (BMI) (Table 1). ${ }^{2}$ It is a poor dosing metric as comparable BMls often represent dissimilar body compositions. However, BMI can be used as a guide and clinicians should start to reconsider drug dosing in patients with a BMI over 30 .

\section{Pharmacokinetics of drugs in obesity}

Without evidence to guide drug dosing in extreme body size, scientific (and physiologically informed) methods rely on an understanding of how body composition influences the pharmacokinetics and pharmacodynamics of drugs. Volume of distribution is important for determining the loading dose and clearance is important to determine the maintenance dose.

\section{Body composition and drug clearance}

Body composition changes with total body weight. Normal-weight patients have a total body weight consisting of lean and adipose body weight in an approximate 4:1 ratio. In obese patients, the excess adipose weight is accompanied by a $20-40 \%$ increase in lean body weight. This results in a lean:adipose weight ratio of approximately 3:2 (see Fig.).

Table 1 Categorisation of body mass index

\begin{tabular}{lc}
\hline Category & Body mass index $\left(\mathbf{k g} / \mathbf{m}^{2}\right)$ \\
\hline Normal weight & $18.5-24.99$ \\
\hline Overweight & $25-29.99$ \\
Obese class I & $30-34.99$ \\
\hline Obese class II & $35-39.99$ \\
\hline Obese class III* & $\geq 40$ \\
\hline
\end{tabular}

* The term morbid obesity is synonymous with the definition of obese class III.

Source: Reference 2

\section{Michael Barras}

Deputy director - Clinical Pharmacy Department Princess Alexander Hospital

\section{Amy Legg}

Drug use evaluation pharmacist Pharmacy Department Royal Brisbane and Women's Hospital Brisbane

\section{Keywords}

antibiotics, anticoagulants, drug dosing education, pharmacokinetics, obesity

Aust Prescr 2017:40:189-93 https://doi.org/10.18773/ austprescr.2017.053 


\section{Fig. Body composition in a normal-weight and obese patient}

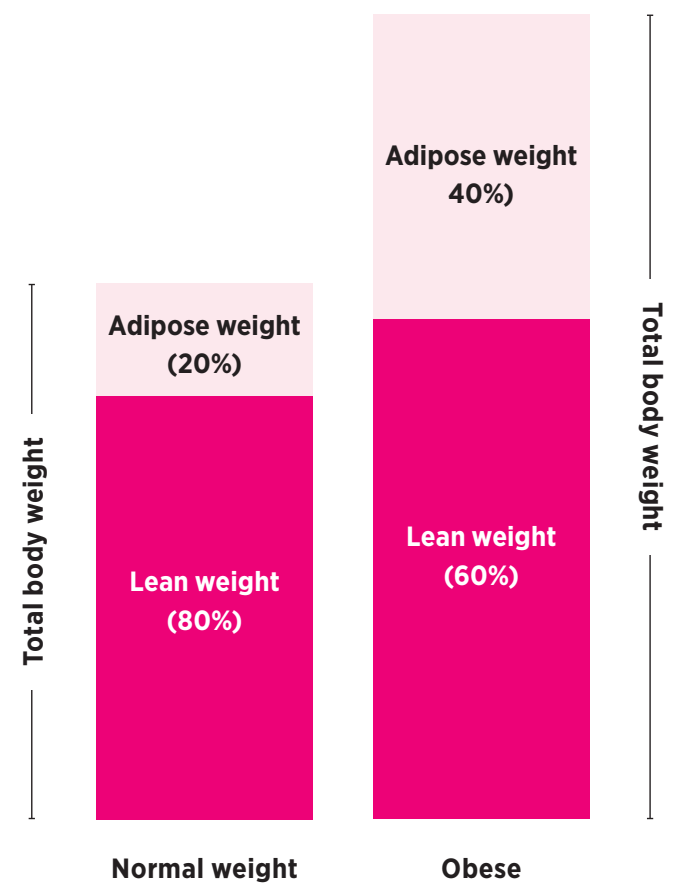

A pictorial comparison of a normal-weight patient $\left(\sim \mathrm{BMl} 25 \mathrm{~kg} / \mathrm{m}^{2}\right)$ and an obese patient $\left(\sim \mathrm{BMI} 30 \mathrm{~kg} / \mathrm{m}^{2}\right)$ highlighting the approximate proportions of lean and adipose weight.
Drug clearance represents the functional capacity of the body to metabolise and excrete a drug. Clearance is correlated to lean rather than adipose weight as adipose tissue has little metabolic activity. ${ }^{12}$

As clearance determines a drug's maintenance dose, clinicians should consider how lean body weight, rather than total body weight, impacts dosing. When lean body weight increases there will be a corresponding increase in drug clearance and an increased dose may be required.

Commonly used weight-based drugs that may require dose adjustment and monitoring in obesity, and in particular morbid obesity, are listed in Table 2. Individual drug monographs in the Australian Medicines Handbook should be consulted to identify if weight-based dosing is required.

Clearance has been correlated with lean body weight for opioids such as fentanyl,,$^{10}$ anaesthetics such as propofol, ${ }^{10}$ ranitidine, lithium and enoxaparin. ${ }^{8}$

\section{Volume of distribution}

Volume of distribution is related to structural aspects of the body. Hydrophilic drugs generally have a high plasma concentration relative to dose, and a smaller volume of distribution. In contrast, lipophilic drugs distribute more readily into adipose tissue, resulting in lower plasma concentrations and a larger volume of distribution.

\section{Table 2 Drugs that require dose adjustment in obesity}

\begin{tabular}{|c|c|}
\hline Drug & Patient monitoring* \\
\hline Low-molecular-weight heparins (enoxaparin, dalteparin) & TDM - anti-Xa monitoring, clinical response \\
\hline Digoxin & TDM - serum digoxin, clinical response \\
\hline Phenytoin & TDM - serum phenytoin, clinical response \\
\hline Aciclovir & clinical response \\
\hline $\begin{array}{l}\text { Antibiotics - macrolide (e.g. erythromycin }{ }^{\dagger} \text { ), } \\
\text { fluoroquinolone (e.g. ciprofloxacin }{ }^{\dagger} \text { ) }\end{array}$ & clinical response, microbiological response \\
\hline $\begin{array}{l}\text { Antibiotics - glycopeptides (e.g. vancomycin), } \\
\text { aminoglycosides (e.g. gentamicin, tobramycin), } \\
\text { beta-lactams }^{\dagger} \text { (e.g. penicillins, cephalosporins) }\end{array}$ & TDM - all, clinical response, microbiological response \\
\hline Antifungals (e.g. amphotericin, voriconazole, fluconazole) & $\begin{array}{l}\text { TDM - serum voriconazole, clinical response, } \\
\text { microbiological response }\end{array}$ \\
\hline Unfractionated heparin & TDM - aPTT monitoring, clinical response \\
\hline Monoclonal antibodies & TDM - clinical response \\
\hline Ciclosporin & TDM - serum ciclosporin, clinical response \\
\hline
\end{tabular}

TDM therapeutic drug monitoring aPPT activated partial thromboplastin time

* Response refers to both effectiveness (e.g. cure) or adverse effects.

+ Dose adjustment is generally required at high intravenous doses. 
Hydrophilic drugs (e.g. aminoglycosides, lithium, aciclovir, glycopeptides, beta-lactams, low-molecularweight heparins) typically remain in extracellular fluid and their volume of distribution correlates with lean mass. This implies that the distribution of hydrophilic drugs should not be significantly influenced by excess adipose tissue.

For lipophilic drugs, volume of distribution is more likely to correlate with total body weight. ${ }^{6}$ Highly lipophilic drugs (phenytoin, midazolam, voriconazole, propofol) distribute extensively into adipose tissue, resulting in a larger volume of distribution compared to less lipophilic drugs.

Drugs with a large volume of distribution often require loading doses followed by a constant dose rate to maintain steady-state plasma concentrations. Steadystate concentrations are dependent on drug clearance.

\section{Body size descriptors used to calculate drug doses}

Several different body descriptors can be used to calculate drug doses (Table 3). ${ }^{13-16}$

\section{Total body weight}

Using total body weight assumes that the pharmacokinetics of the drug are linearly scalable from normal-weight patients to those who are obese. This is inaccurate. For example, we cannot assume that a $150 \mathrm{~kg}$ patient eliminates a drug twice as fast as a $75 \mathrm{~kg}$ patient and therefore double the dose. Clinicians are alert to toxicities with higher doses, for example nephro- and neurotoxicity with some antibiotics and chemotherapeutics, and bleeding with anticoagulants. Arbitrary dose reductions or 'caps' are used to avoid these toxicities, but if too low can result in sub-therapeutic exposure and treatment failure. ${ }^{6,11,12}$

\section{Lean body weight}

Using a lean body weight metric encompasses a more scientific approach to weight-based dosing. Lean body weight reflects the weight of all 'non-fat' body components, including muscle and vascular organs such as the liver and kidneys. As lean body weight contributes to approximately $99 \%$ of a drug's clearance, ${ }^{5}$ it is useful for guiding dosing in obesity.

This metric has undergone a number of transformations. The most commonly cited formula derived by $\mathrm{Cheymol}^{7}$ is not optimal for dosing across body compositions and can even produce a negative result. A new formula has been developed (see Table 3) that appears stable across different body sizes, in particular the obese to morbidly obese..$^{15}$

A practical downfall of the calculation of lean body weight (and other body size descriptors) is the numerical complexity, which may not be palatable to a busy clinician. Often limited time is available for prescribing and an immediate calculation is required. Lean body weight calculators are available online, for example in the Therapeutic Guidelines. ${ }^{17}$

\section{Adjusted body weight}

Calculating doses based on adjusted body weight is mainly used for aminoglycoside antibiotics. ${ }^{14}$ It was developed to account for adipose tissue, which does not affect drug clearance. A correction factor of 0.4 is used to estimate adjusted body weight (Table 3). The aminoglycosides dose is then calculated using the resultant weight. This descriptor is rarely used in other drug classes, although there is some evidence for other antibiotics in the morbidly obese..$^{9,14}$

\section{Body surface area}

Body surface area $^{16}$ is traditionally used to dose chemotherapeutics. It is a function of weight and height and has been shown to correlate with cardiac output, blood volume and renal function. However, it is controversial in patients at extremes of size because it does not account for varying body compositions. As a consequence, some older drugs such as cyclophosphamide, paclitaxel and doxorubicin were 'capped' (commonly at $2 \mathrm{~m}^{2}$ ) potentially resulting in sub-therapeutic treatment." Recent guidelines suggest that unless there is a justifiable reason to reduce the dose

\section{Table 3 Body size descriptors commonly used in drug dosing}

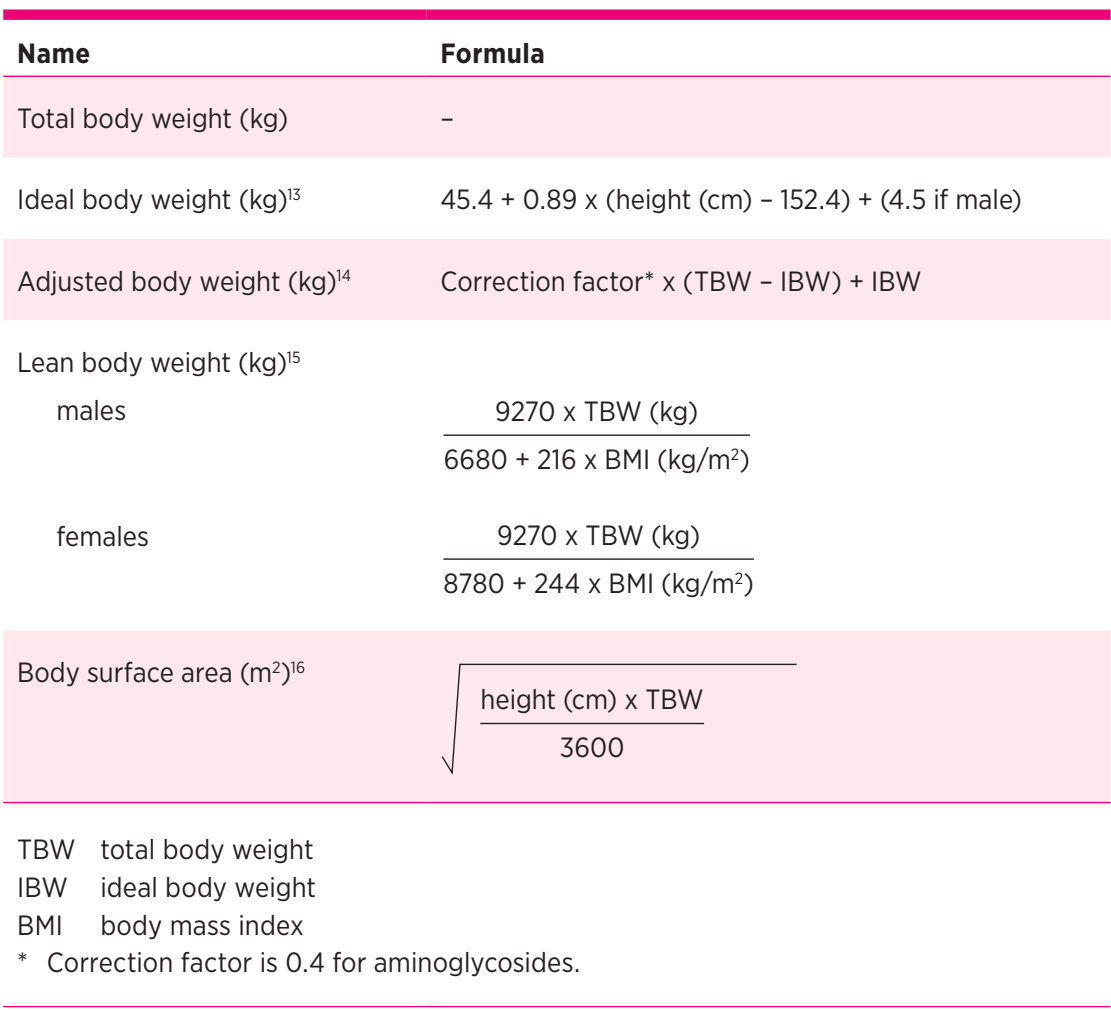


(e.g. renal disease), total body weight should be used in the calculation of body surface area, until further research is done." Little research into dosing based on body surface area has been conducted for other medicines.

\section{Ideal body weight}

Ideal body weight was developed for insurance purposes not for drug dosing. ${ }^{13}$ It is a function of height and gender only and, like body surface area, does not take into account body composition. Using ideal body weight, all patients of the same height and sex would receive the same dose, which is inadequate and generally results in under-dosing. ${ }^{4}$ For example a male who has a total body weight of $150 \mathrm{~kg}$ and a height of $170 \mathrm{~cm}$ will have the same ideal body weight as a male who is $80 \mathrm{~kg}$ and $170 \mathrm{~cm}$ tall. Both could potentially receive a $\mathrm{mg} / \mathrm{kg}$ dose based on $65 \mathrm{~kg}$ (ideal body weight).

\section{Calculating drug doses}

The clinical issue is that calculating drug doses using each body size descriptor will result in a different weight. Consider dosing a $150 \mathrm{~kg}$ man who is $170 \mathrm{~cm}$ tall. Rounded to the nearest $5 \mathrm{~kg}$, his body size descriptors are:

- total body weight $=150 \mathrm{~kg}$

- $\quad$ lean body weight = $(9270 \times 150) / 6680+216 \times\left(150 / 1.7^{2}\right)=80 \mathrm{~kg}$

- $\quad$ ideal body weight $=$ $45.4+0.89 \times(170-152.4)+4.5=65 \mathrm{~kg}$

Obviously, large variations exist for $\mathrm{mg} / \mathrm{kg}$ dosing depending on which metric is used.

\section{Enoxaparin}

A pertinent example of this dilemma is enoxaparin, a hydrophilic anticoagulant. Its licensed dose for treatment of venous thromboembolism is based on total body weight $(\mathrm{mg} / \mathrm{kg}$ ). Many clinicians recognise that this results in high doses in obesity and increases the risk of toxicity, so they reduce or cap the dose (often at $100 \mathrm{mg}$ ) in patients over $100 \mathrm{~kg} .^{18}$ This may result in sub-therapeutic anti-Xa concentrations, particularly in morbid obesity, as clearance increases with body size.

A dose based on lean body weight is warranted in this case and a dose of $1.5 \mathrm{mg} / \mathrm{kg}$ (lean body weight) has been proposed. ${ }^{8}$ In the above example, the $150 \mathrm{~kg}$ male would receive $120 \mathrm{mg}$ twice daily (rounded up), that is $1.5 \times 80 \mathrm{~kg}$.

The prophylactic dose is usually $20-40 \mathrm{mg}$ daily. As clearance increases with body size, the dose should be increased in morbid obesity and suggested doses include 30-40 mg twice daily..$^{19}$

\section{Unfractionated heparin}

In thrombotic diseases, unfractionated heparin is dosed using total body weight. An initial bolus (units $/ \mathrm{kg}$ ) is followed by a continuous infusion (units $/ \mathrm{kg} /$ hour) and adjusted based on the activated partial thromboplastin time (aPTT). However, nomograms often use a dose cap (bolus and maintenance) in obese patients. This can lead to undertreatment, and increased monitoring is recommended. Like enoxaparin, the prophylactic dose should be increased in morbid obesity, for example 5000 units three times a day or 7500 units twice daily.

\section{Carvedilol, apixaban, ribavirin and prasugrel}

Some drugs have a licensed dichotomised dose based on total body weight. The maximum daily dose of carvedilol is $50 \mathrm{mg}$ in patients weighing less than $85 \mathrm{~kg}$ and $100 \mathrm{mg}$ for patients weighing $85 \mathrm{~kg}$ or more. Consequently a patient weighing $86 \mathrm{~kg}$ would receive twice the dose of a patient weighing $84 \mathrm{~kg}$. Dichotomised dose strategies can result in underand overdosing and should be used with caution in patients with obesity. Apixaban, ribavirin and prasugrel have similar dosing recommendations.

\section{Cephazolin}

Cephalosporins are often prescribed as surgical prophylaxis. Due to the increase in clearance in obese patients, the dose should be increased. ${ }^{9}$ The recommended dose of $1 \mathrm{~g}$ has been increased to $2 \mathrm{~g}$ in obese patients to ensure adequate exposure and may need to be administered more frequently.

\section{Conclusion}

Estimating the optimal dose for obese patients is difficult and, in many cases, ill defined. Basing maintenance doses on total body weight is unlikely to result in a comparable drug response across different body sizes and generally increases the risk of adverse events. Individualised dosing based on the patient's lean body weight is recommended, with accompanying therapeutic drug monitoring and monitoring of the patient's clinical response.

Designing clinical trials that stratify doses across a range of body weights will improve drug-dosing knowledge. In the meantime, we need to rely on scientific principles to dose many drugs in the obese. $\varangle$

Conflict of interest: none declared 


\section{REFERENCES}

1. Australian Bureau of Statistics. Overweight and obsesity. In: National health survey: first results, 2014-15. ABS Catalogue No. 4364.0.55.001. Canberra: Australian Government; 2015. www.abs.gov.au [cited 2017 Sep 1]

2. World Health Organization. Health topics: Obesity. Geneva: WHO; 2016. www.who.int/topics/obesity/en [cited 2017 Sep 1]

3. Jain R, Chung SM, Jain L, Khurana M, Lau SW, Lee JE, et al. Implications of obesity for drug therapy: limitations and challenges. Clin Pharmacol Ther 2011;90:77-89. https://doi.org/10.1038/clpt.2011.104

4. Green B, Duffull SB. What is the best size descriptor to use for pharmacokinetic studies in the obese? Br J Clin Pharmacol 2004;58:119-33. https://doi.org/10.1111/ j.1365-2125.2004.02157.x

5. Morrish GA, Pai MP, Green B. The effects of obesity on drug pharmacokinetics in humans. Expert Opin Drug Metab Toxico 2011;7:697-706. https://doi.org/10.1517/17425255.2011.570331

6. Hanley MJ, Abernethy DR, Greenblatt DJ. Effect of obesity on the pharmacokinetics of drugs in humans Clin Pharmacokinet 2010;49:71-87. https://doi.org/10.2165/ 11318100-000000000-00000

7. Cheymol G. Effects of obesity on pharmacokinetics: implications for drug therapy. Clin Pharmacokinet 2000;39:215-31. https://doi.org/10.2165/00003088-200039030-00004

8. Green B, Duffull SB. Development of a dosing strategy for enoxaparin in obese patients. Br J Clin Pharmaco 2003:56:96-103. https://doi.org/10.1046/j.1365-2125.2003.01849x

9. Janson B, Thursky K. Dosing of antibiotics in obesity. Curr Opin Infect Dis 2012;25:634-49. https://doi.org/10.1097/ QCO.0b013e328359a4c

10. Ingrande J, Lemmens $\mathrm{HJ}$. Dose adjustment of anaesthetics in the morbidly obese. Br J Anaesth 2010;105 Suppl 1:i16-23. https://doi.org/10.1093/bja/aeq312

11. Griggs JJ, Mangu PB, Anderson H, Balaban EP, Dignam JJ, Hryniuk WM, et al.; American Society of Clinical Oncology. Appropriate chemotherapy dosing for obese adult patients with cancer: American Society of Clinical Oncology clinical practice guideline. J Clin Oncol 2012:30:1553-61. https://doi.org/10.1200/JCO.2011.39.9436
12. Han PY, Duffull SB, Kirkpatrick CM, Green B. Dosing in obesity: a simple solution to a big problem. Clin Pharmacol Ther 2007;82:505-8. https://doi.org/10.1038/ sj.clpt.6100381

13. Pai MP, Paloucek FP. The origin of the "ideal" body weight equations. Ann Pharmacother 2000;34:1066-9. https://doi.org/10.1345/aph.19381

14. Bauer LA, Edwards WA, Dellinger EP, Simonowitz DA Influence of weight on aminoglycoside pharmacokinetics in normal weight and morbidly obese patients. Eur J Clin Pharmacol 1983:24:643-7.

15. Janmahasatian S, Duffull SB, Ash S, Ward LC, Byrne NM, Green B. Quantification of lean bodyweight. Clin Pharmacokinet 2005;44:1051-65. https://doi.org/ 10.2165/00003088-200544100-00004

16. Mosteller RD. Simplified calculation of body-surface area. N Engl J Med 1987;317:1098. https://doi.org/10.1056/ NEJM198710223171717

17. Calculators. In: eTG complete [Internet]. Melbourne: Therapeutic Guidelines Limited; 2017. https://tgldcdp.tg.org.au/ calculator?type=Calculators [cited 2017 Sep 1]

18. Barras MA, Kirkpatrick CM, Green B. Current dosing of low-molecular-weight heparins does not reflect licensed product labels: an international survey. Br J Clin Pharmacol 2010;69:520-8. https://doi.org/10.1111/ j.1365-2125.2010.03626.x

19. Nutescu EA, Spinler SA, Wittkowsky A, Dager WE. Lowmolecular-weight heparins in renal impairment and obesity: available evidence and clinical practice recommendations across medical and surgical settings. Ann Pharmacother 2009:43:1064-83. https://doi.org/10.1345/aph.1L194

\section{FURTHER READING}

Day RO, Snowden L. Where to find information about drugs. Aust Prescr 2016;39:88-95. https://doi.org/10.18773/ austprescr.2016.023 